\title{
Family Functioning and Functional Independence in Spinal Cord Injury Adjustment
}

\author{
M. B. McGowan, M.S., R.N., ${ }^{1}$ S. Roth, Ph.D. ${ }^{2}$ \\ ${ }^{1}$ Curaflex Health Services, Houston, Texas 77092, U.S.A. ${ }^{2}$ Department of \\ Physical Medicine and Rehabilitation, University of Michigan, Ann Arbor, MI \\ 48109, U.S.A.
}

\begin{abstract}
Summary
The relationships among functional independence, perceived family functioning and duration of disability were studied in 41 non-institutionalised post-traumatic spinal cord injury (SCI) families. Correlational analyses revealed that SCI subjects with greater self initiation of activities, increased social involvement and higher overall level of independence perceived their family environment as affectively responsive, open in communication and clear in delineation of role responsibilities. The 'significant other's' ( $A$ 'significant other' is designated by the SCI subject as 'the one most involved with you'. The 'significant other' had to be living with or within 25 miles of the SCI subject and in contact at least 3 times a week.) view of the family was unrelated to SCI function. Conversely, for the significant other but not the SCI subject, greater duration of disability predicted more concern for the family's ability to problem solve, delineate roles and maintain standards of behaviour control. Of the functional areas measured, only participation in outside activities increased significantly over time. The results are discussed in terms of the importance of considering the long-term and separate rehabilitation needs of the individual with a SCI and his or her family.
\end{abstract}

Key words: Spinal cord injuries; Paraplegia; Quadriplegia; Physical disability; Family relationships.

\section{Introduction}

The impact of a trumatic spinal cord injury (SCI) extends beyond acquired limitations in mobility and self care to effect fundamental changes in family process (Bartol, 1978; Bishop, Epstein and Baldwin, 1982; Hohmann, 1975). The nature of the relationship between the disabled member and family can determine the SCI person's emotional reaction to his or her injury (Harris et al., 1973; Klein et al., 1967) and thereby influence the course of rehabilitation (Bracken and Shepard, 1980; Dinsdale et al., 1971). Unfortunately the family's ability to support rehabilitation efforts may be compromised by the abrupt and 
pervasive demands for change placed on the family system by permanent disability (Mailick, 1979; Steinglass et al., 1982). In this regard clinical reports describe a shift in patterns of communication (Mailick, 1979; Rohrer et al., 1980; Weller and Miller, 1977b), emotional intimacy (Bracken and Shepard, 1980; Cleveland, 1979) and role identification (Klein et al., 1967; Shellhase and Shellhase, 1972) within SCI families. Failure to adequately address problems in family adaptation to SCI may be critical to understanding negative treatment outcome in SCI rehabilitation (Hohmann, 1979; Trieschman, 1980).

Despite the general agreement that effective SCI rehabilitation requires consideration of patient-family dynamics there have been few experimental studies to investigate those aspects of family functioning which positively influence therapeutic outcome. The majority of SCI family research comprises statistical summaries on the effect of SCI trauma on marital stability (Crewe et al., 1979; DeVivo and Fine, 1985; El Ghatit and Hansen, 1975; 1976) and descriptive accounts (Mailick, 1979; Rohrer et al., 1980; Weller and Miller, 1977a; 1977b) or case observations (Cleveland, 1979; White, 1983) of SCI families undergoing acute rehabilitation. In a study of SCI treatment outcome Richards et al. (1980) report that SCI subjects who had more pain related disability were members of families with greater psychosocial dysfunction as assessed by staff ratings. Unfortunately, in this study as in others (Litman, 1962) the use of nonstandardised measures of family process compromises the validity and generalisability of the findings.

It is reasonable to assume that the nature of the interaction between the SCI member and family is not static but changes over time (Cleveland, 1979; Woodrich and Patterson, 1980). Steinglass et al. (1982) contend that in facing the acute crisis of SCI, families may focus their ability to cope on maintaining short time stability while neglecting, and thus sacrificing, long term needs.

Family members may become resentful after their initial demonstration of support if long-term rehabilitation outcome falls short of expectations (Wittkower et al., 1954). Duration of disability as a subject variable has been virtually ignored by SCI researchers (Trieschman, 1980). While there is evidence that duration of disability is associated with greater acceptance of SCI (Woodrich and Patterson, 1980) some patients may actually deteriorate in their adjustment over time (Rosensteil and Roth, 1981). As several authors note (Kerr and Thompson, 1972; Stewart, 1977-78; Trieschman, 1980), it may be years before an individual is fully reconciled to the harsh realities of SCI. The failure to study the longitudinal aspects of SCI adjustment has hampered a broader understanding of the chronic effects of traumatic SCI on family process.

This study examines the relationship between family functioning and adjustment to disability among a post-rehabilitation SCI population. Measures of family process were obtained separately from the SCI individual and his or her significant other utilising the Family Assessment Device (Epstein et al., 1983) a standardised measure of family functioning. SCI adjustment was defined in terms of several aspects of functional independence (e.g. activities of daily living, social involvement, etc). In addition, SCI subjects were categorised according to their duration of disability to determine if perceptions of family process and observed levels of functional ability vary with time. 


\section{Patients and methods}

\section{Subjects}

Eighty SCI individuals whose names were obtained from the rehabilitation service of a large midwestern teaching hospital were contacted by telephone to seek their participation in a study on 'adjustment to SCI.' From this pool 41 persons (male $=34$, female $=7$ ) agreed to participate and met the further criteria that they be living in a private house or apartment and be free of cognitive impairment. The 39 individuals who did not participate either did not respond to the invitation to be in the study or did not have a 'significant other'. Subjects ranged in age from 21 to 48 years with a mean of 28.8 years $(\mathrm{SD}=$ $6 \cdot 87)$. All injuries were trauma induced with motor vehicle accidents accounting for 22 of the injuries while sports-related accidents accounted for 13 . The subject pool included 26 quadriplegics and 15 paraplegics (including three subjects with incomplete cervical injuries permitting normal use of their upper but not lower extremities). A 'significant other' was designated by the SCI subject defined as 'the one most involved with you'. The significant other had to be living with $(\mathrm{n}=34)$ or within 25 miles of the SCI subject and in contact at least three times a week $(\mathrm{n}=7)$.

\section{Instruments}

Assessment of SCI Functional Independence. The functional ability of the SCI subject was assessed by the Functional Life Scale developed by Sarno, Sarno and Levita (1973). The FLS solicits an observer rating of level of independence for various functional areas according to a four point scale from 'not at all' to 'normal'. Specifically the tool assesses level of independence across five categories: activities of daily living, home activities, outside activities, cognition and social interaction. For this study measures of cognition were not obtained. The four remaining variables were compiled to derive a global functional independence score. Beyond these measures the FLS also provides ratings of self-initiation, speed, frequency and overall efficiency of activities. For all variables higher scores signify greater independence. In this sample, student t-tests computed for SCI subjects across the nine FLS scores found paraplegics performing at significantly higher levels of independence than quadriplegics for all FLS factors providing construct validity for the FLS as a measure of functional independence for a SCI population.

Assessment of Family Functioning. The Family Assessment Device (Epstein et al., 1983) is a sixty item self report scale which assesses six dimensions of family functioning as well as overall level of functioning. The subscales include: Problem Solving, Communication, Roles, Affective Responsiveness, Affective Involvement, Behaviour Control, and General Functioning. Problem solving refers to the family's ability to resolve problems to a level that maintains effective family functioning. The communication scale assesses whether communication is clear or masked with respect to content. The roles scale focuses on whether the family has established patterns of behaviour for handling family tasks. Affective responsiveness assesses the extent to which individual family 
members are able to experience appropriate affect over a range of situations. affective involvement is concerned with the extent to which family members are interested in and place value on each other's activities and concerns. Behaviour control assesses the way in which a family maintains standards for the behaviour of its members. Finally, the general functioning scale provides an overall assessment of the level of family functioning.

The FAD has been found to have acceptable levels of internal consistency, test-retest reliability, concurrent validity, and discriminative validity (Epstein et al., 1983). Health/pathology cut-off scores based on the relationship of the FAD to expert clinicians' ratings of the family have been developed and have acceptable levels of sensitivity and specificity (Miller et al., 1983).

\section{Procedure}

Two copies of the FAD were mailed to each participating group and were completed independently by the SCI subject and the significant other. Upon return of the completed questionnaire telephone interviews were conducted with the significant other to obtain the FLS measurements.

\section{Results}

Functional independence and family functioning. Pearson product moment correlations were computed across subscale scores of the FLS and FAD to determine if the SCI subjects level of functional ability was related to perceptions of the family environment. Several significant correlations were obtained. SCI subjects who exhibited greater self initiation of activity rated their families as high in affective responsiveness $(\mathrm{r}=-0.40, \mathrm{p}<0.01)$ and affective involvement $(\mathrm{r}=-0.33, \mathrm{p}<0.05)$ clear and direct in their communication $(\mathrm{r}=-0.40$, $\mathrm{p}<0.01)$, effective in the distribution of role responsibilities $(r=-0.34$, $\mathrm{p}<0.05)$ and positive for a global measure of healthy family functioning $(\mathrm{r}=$ $-0.31, p<0.05)$. Increased social interaction was associated with a family environment characterised by affective responsiveness $(\mathrm{r}=-0.35, \mathrm{p}<0.05)$, good communication $(\mathrm{r}=-0.47, \mathrm{p}<0.01)$ and clear delineation of roles $(\mathrm{r}=$ $-0.31, p<0.05)$. Those SCI subjects judged high in frequency of activity involvement tended to assess their family as affectively responsive $(r=-0.35$, $\mathrm{p}<0.05)$. Finally, SCI subjects rated highest on a global score of functional independence found their family members to be both affectively responsible $(\mathrm{r}=-0.33, \mathrm{p}<0.05)$ and open in their communication $(\mathrm{r}=-0.33, \mathrm{p}<0.05)$.

For the significant other, correlations computed for FLS and FAD scores yielded no significant relationships. This finding indicates that the level of independence achieved by the SCI subject was independent of the significant other's view of the family environment.

Perceptions of family functioning. Correlations computed on FAD scores for each SCI subject-significant other cohort were significant for the following family factors: general functioning $(\mathrm{r}=0.49, \mathrm{p}<0.01)$, affective involve $(\mathrm{r}=$ $0.48, \mathrm{p}<0.01)$, behaviour control $(\mathrm{r}=0.45, \mathrm{p}<0.01)$, communication $(\mathrm{r}=$ $0.42, \mathrm{p}<0.01)$ and affective responsiveness $(\mathrm{r}=0.33, \mathrm{p}<0.05)$. Taken 
together, these findings suggest general agreement within the group on their perceptions of family interaction.

Level of injury and family functioning. To determine if perception of the family differed according to the level of injury, student t-tests were performed on the seven FAD factors comparing quadriplegic and paraplegic subjects. No significant differences were obtained. Similarly, t-tests comparing the significant others FAD scores for the respective SCI groups revealed no differences on any FAD factor.

Duration of disability and family functioning. To analyse the effects of duration of disability on both the perceptions of the family and the SCI subject's level of function subjects were divided into three groups: those who had been disabled for less than 2 years $(\mathrm{n}=12$, nine quadriplegics and three paraplegics), from 2 to 5 years $(n=15$, nine quadriplegics and six paraplegics), and more than 5 years ago $(n=14$, eight quadriplegics and six paraplegics). A one-way analysis of variance (ANOVA) performed on SCI subjects' FAD scores across the duration of disability factor yielded no significant differences. Thus, SCI subjects did not differ in their rating of family functioning regardless of the duration of their disability.

A one-way ANOVA performed across the duration of disability groups for significant others' FAD scores revealed a number of significant findings. Problem solving ability $(\mathrm{F}=4.07, \mathrm{df}=40, \mathrm{p}<0.05)$, roles $(\mathrm{F}=4.42, \mathrm{df}=$ $40, \mathrm{p}<0.05)$ and the ability to maintain standards for behaviour control $(\mathrm{F}=$ $4 \cdot 10, \mathrm{df}=40, \mathrm{p}<0.05)$ were perceived as significantly impaired over time. Multiple internal comparisons utilising the Scheffe test were computed across the duration of disability groups. The problem-solving factor measuring effectiveness in conflict resolution was perceived as significantly greater for the less than 2 year post-injury group compared to both the 2 to 5 ( $F=5.08$, $\mathrm{p}<0.05)$ and 5 year post-injury groups $(\mathrm{F}=7.27, \mathrm{p}<0.05)$. Similarly, significant differences were obtained for the roles factor indicating better distribution of role responsibilities for the most acute post-injury SCI families when compared with both the 2 to $5(\mathrm{~F}=5.03, \mathrm{p}<0.05)$ and 5 year $(\mathrm{F}=8 \cdot 19$, $\mathrm{p}<0.01)$ post-injury groups. Significant differences were also obtained when comparing the less than 2 and greater than 5 year injury groups $(F=7 \cdot 81$, $\mathrm{p}<0.01$ ) indicating reduced maintenance of standards of behaviour control with greater duration of disability.

Duration of disability and functional independence. A one-way ANOVA was performed on FLS scores across the three duration of injury groups to determine whether time since injury influenced functional ability. A significant effect for outside activity $(\mathrm{F}=3.80, \mathrm{df}=40, \mathrm{p}<0.05)$ was obtained. Subjects who were less than 2 years post-injury were less likely to be involved in outside activities than those who had been injured beyond 5 years $(t=2 \cdot 58$, df $=24$, $\mathrm{p}<0.05)$. No other significant main effects were obtained.

\section{Discussion}

This study addressed the covariation of two adjustment factors, functional independence and duration of disability, with family functioning among a posttrumatic SCI population. The results provide empirical support for the positive 
association of a healthy family environment and achieved levels of independence while raising concerns regarding the long-term effects of chronic disability on SCI family process. By obtaining independent measures of family functioning it was possible to assess the degree of concordance between the SCI subject and significant other in their assessment of family interactions and how these perceptions correlate with the two adjustment questions of interest. In this sample there appeared to be general consensus on the nature of family interactions with SCI subjects and their significant others agreeing on 7 of the 9 measures of family functioning obtained. Similarly, there were no differences in ratings of family health for both SCI subjects and significant others regardless of whether the former was quadriplegic or paraplegic. However, when comparing family ratings with measures of functional independence and the duration of disability factor important differences within the group arise. The prediction of improved SCI functional independence was obtained when the SCI subject, but not the significant other, viewed the family with greater positive regard. On the other hand, only the significant other perceived a decline in the coherence of family functioning with increased chronicity of disability.

When considering the positive association of a healthy family environment with greater SCI functional ability the data suggests that three functional dimensions, namely self-initiation, social involvement and overall functional independence, were most consistently impacted by family process variables. Importantly, the family factors found to significantly correlate with these functional areas were affective responsiveness, roles and communication. These three family variables have been frequently cited by rehabilitation specialists to be crucial in facilitating patient and family adjustment following SCI (Cleveland, 1979; Mailick, 1979). The correlational nature of the analysis does not permit an inference of causality. Thus whether these associations represent the therapeutic contribution of the family on SCI functional ability or, conversely, reflects the likelihood of improved family satisfaction for the SCI subject who achieves greater functional independence cannot be ascertained. The fact that quadriplegic and paraplegic subjects did not differ in their perceptions of family functioning suggests against the former interpretation. Alternatively, clinical observations may explain the manner in which affective responsiveness, open communication and effective resolution of transformations in role identification can promote optimal SCI adjustment.

During the initial period following injury the SCI person may experience severe emotional reactions such as anger, depression and alienation (Bracken and Shepard, 1980; Weller and Miller, 1977a). Family members must cope with these reactions while simultaneously addressing their own feelings of frustration and victimisation (Mailick, 1979). Nurturing feedback from the family can be crucial to preserving the disabled members' self-esteem and self-worth by reinforcing their value as members of a family system (Bartol, 1987; Hamburg and Adams, 1967). As Mailick (1979) suggests, free and direct exchange of feelings and attitudes among family members may be essential to achieving the long-term role adjustments necessary for reintegration of the SCI member into the family system. In this way the family may serve as an emotional 'buffer' (Cobb, 1976) for the individual who must negotiate the severe physical and psychological adaptations associated with permanent paralysis. 
It appears that for significant others the degree to which the family environment is viewed as healthy is not influenced by the functional independence of the SCI member. The failure to obtain a relationship between the significant others' ratings of SCI independence and family functioning may be the result of methodological constraints on the selection of significant others. Seven of the partners were not living with the SCI subject. The mix of significant others was quite hererogeneous including mothers, siblings, spouses, companions, and children. The definition of the 'family' may have been less clearly definable for this group thereby influencing their assessment of the family system and, as a result, the correlation of family and function variables. However, this finding may represent the fact that for significant others the reinforcement for family satisfaction rests beyond the functional ability of the SCI family member. In this regard the lack of correlation may reflect the significant others' disappointment with long-term rehabilitation outcome. For example, SCI subjects evidenced minimal functional gains with only one function variable, involvement in outside activity, being rated as significantly greater across time.

For this study, significant others of SCI subjects with at least a five year history of disability reported greater impairment for the family's ability to distribute role responsibilities, problem-solve and maintain standards of behaviour control when compared with their counterparts whose SCI partners were more acutely disabled. Thus, it appears that SCI family functioning, at least from the significant others' perspective, does not improve with the passage of time but may actually worsen. Trieschmann (1980) noted the paucity of data concerning the long-term adjustment problems confronted by SCI families and the need for ongoing evaluation and intervention in addressing these issues. These data support the view of Webb et al. (1982) and others (Cleveland, 1979; Weller and Miller, 1977b) who have suggested that the stress of living with an SCI individual does not resolve with time and, in fact, marital and family problems may become most prevalent years after the onset of injury. As Steinglass et al. (1982), observed, coping with the longitudinal implications of chronic disability requires different strategies than those elicited by the abrupt but transient demands placed on the family system during the acute phase. The availability of family therapy services such as support groups (Rohrer et al., 1980) may be necessary to assist family members in reconciling the ongoing physical and psychological stresses involved with having an SCI family member (Hart, 1981; Shellhase and Shellhase, 1972).

\section{Acknowledgement}

We would like to express our appreciation to the following people for their assistance in preparing this article: Duane Bishop, Theodore Cole, Steve Geiringer, Ned Kirsch, Frederick Maynard and Barbara Zekany.

This research was partially supported by a grant from the Rho Chapter of Sigma Theta Tau.

\section{References}

BARTol G 1978 Psychological needs of the spinal cord injured person. Fournal of Neurosurgical Nursing 10:171-175.

Bishop DS, Epstein NB, Baldwin LM 1982 Disability: A family affair. In Freeman DS, Trute B (eds): Treating Families with Special Needs, Alberta Association of Social Workers. Alberta, Canada. 
Bracken MB, Shepard MJ 1980 Coping and adaptation following acute spinal cord injury: A theoretical analysis. Paraplegia 18:74-85.

CARLSON CE 1979 Conceptual style and life satisfaction following spinal cord injury. Archives of Physical Medicine Rehabilitation 60:346-352.

Cleveland M 1979 Family adaptation to the trumatic spinal cord injury of a son or daughter. Social Work in Health Care 4:459-471.

Совв S 1976 Social support as a moderator of life stress. Psychosomatic Medicine 38:301-314.

Crewe NMM, Athelstom GI, Krumberger J 1979 Spinal cord injury: A comparison of preinjury and post-injury marriages. Archives of Physical Medicine Rehabilitation 60:252-256.

DEVIVo MJ, FINE PR 1985 Spinal cord injury: Its short-term impact of marital status. Archives of Physical Medicine and Rehabilitation 66:501-504.

DinSDALE SM, LeSSER AL, JUdD F 1971 Critical psycho-social variables affecting outcome in a regional spinal cord center. Proceedings of the Veterans Administration Spinal Cord Injury Conference 18:193-196.

El Ghatit A, Hanson R 1975 Outcome of marriages existing at the time of a male's spinal injury. Fournal of Chronic Disease 28:383-388.

El Ghatit AZ, Hanson R 1976 Marriage and divorce after spinal cord injury. Archives of Physical Medicine and Rehabilitation 17:470-472.

EPSTEIN NB, BALDwin LM, Bishop DS 1983 The McMaster Family assessment device. fournal of Marital and Family Therapy 9:171-180.

HAMBURG OA, ADAMS JE 1967 A perspective on coping: seeking and utilizing information in major transitions. Archives of General Psychiatry 17:277-284.

Harris P, Patel SS, Greer W, Naughtoh JAL 1973 Psychological and social reactions to acute spinal paralysis. Paraplegia 2:132-136.

HART G 1981 Spinal cord injury: Impact on client's significant others. Fournal of the Association of Rehabilitation Nursing 1:11-15.

HoHMAN NGW 1975 Psychological aspects of treatment and rehabilitation of the spinal cord injured person. Clinical Orthopedics and Related Research 112:81-88.

KERR W, THOMPSON M 1972 Acceptance of disability of sudden onset in paraplegia. International fournal of Paraplegia 10:94-102.

KLEIN RF, DEAN A, BogdonofF MD 1967 The impact of illness upon the spouse. Fournal of Chronic Disease 20:241-248.

KRUEGER DW 1981-82 Emotional rehabilitation of the physical rehabilitation patient. International Fournal of Psychological Medicine 11:183-191.

Litman TJ 1962 Self-conception and physical rehabilitation. In Rose, AM: Human Behaviour and Social Processes. Boston: Houghton, Mifflin Company, 550-574.

MAILICK M 1979 The impact of severe illness on the individual and family: an overview. Social Work in Health Care 5:117-128.

Miller IW, Epstein NB, Bishop DS, KeItNER GI 1983 The McMaster family assessment device: Reliability and validity. Fournal of Marital and Family Therapy 9:171-180.

Richards JS, MEREdith RL, Nepomunceno C, et al. 1980 Psychological aspects of chronic pain in spinal cord injury. Pain 8:355-366.

Rohrer K, Adelman B, Puchett J, et al. 1980 Rehabilitation in spinal cord injury: Use of a patient-family group. Archives of Physical Medicine and Rehabilitation 61:225-229.

RoSENSTIEL AK, ROTH S 1981 Relationship between cognitive activity and adjustment in four spinal-cord injured individuals: A longitudinal investigation. Fournal of Human Stress 3:3543.

Sarno JE, Sarno MT, Levita E 1973 The functional life scale. Archives of Physical Medicine and Rehabilitation 54:214-220.

Shellhase LJ, SHellhase FE 1972 Role of the family in rehabilitation. Social Casework 11:544550.

Steinglass P, Temple S, Lisman SA, Reiss D 1982 Coping with spinal cord injury: The family perspective. General Hospital Psychiatry 4:259-264.

STEWART TD 1977-78 Coping behavior and the moratorium following spinal cord injury. Paraplegia 15:338-342.

Trieschman RB 1974 Coping with a disability: A sliding scale of goals. Archives of Physical Medicine and Rehabilitation 55:556-560.

Trieschman RB 1980 Spinal cord injuries: Psychological, social and vocational adjustment. New York, Pergamon Press Inc.

Weller DJ, Miller P 1977a Emotional reactions of patient, family, and staff in the acute-care period of spinal cord injury: Part 1. Social Work in Health Care 3:7-17.

Weller DJ, Miller P 1977b Emotional reactions of patient, family, and staff in the acute-care period of spinal cord injury: Part 2. Social Work in Health Care 2:369-377. 
WebB SB, Lorenzi E, Berzins E 1982 Marital, educational, employment, income and general financial status prior to and one to six years post SCI. Paraplegia 20:108-109.

WHITE LJ 1983 The adjustment process of the spinal cord injured: case study reports. Doctorial Dissertation, Oklahoma State University.

WitTkower ED, Gingras G, MERGLER L 1954 A combined psychosocial study of spinal cord lesions. Canadian Medical Association fournal 7:109-115.

Woodrich F, PAtTerson JB 1980 Variables related to acceptance of disability in persons with spinal cord injuries. Fournal of Rehabilitation 3:26-39. 